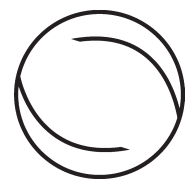

\title{
Organizing R\&D Consortia for Path Creation and Extension: The Case of Semiconductor Manufacturing Technologies
}

Organization Studies 33(7) 907-936

(c) The Author(s) 2012

Reprints and permission: sagepub.co.uk/journalsPermissions.nav DOI: I0.1 I77/0I708406/2448029

www.egosnet.org/os

\section{Jörg Sydow}

Freie Universität Berlin, Germany

\section{Arnold Windeler}

Technische Universität Berlin, Germany

\section{Cornelius Schubert}

Technische Universität Berlin, Germany

\section{Guido Möllering}

Jacobs University Bremen, Germany

\begin{abstract}
Taking issue with the classical theory of path dependence, we capture the active agency involved in collective efforts aimed at extending a current technological path and, in parallel, at creating a new path in the field of leading-edge international semiconductor manufacturing. We apply structuration theory in order to analyse the practices of path constitution that traditional evolutionary views of lock-in and irreversibility in path processes have neglected. Drawing on 96 interviews since 2003 and extensive secondary sources in the field of semiconductor manufacturing in Europe, Japan and the United States, we perform a qualitative, longitudinal and multi-level case analysis; in this analysis we trace, in particular, the strategic development of a path-extending technological option besides a potentially path-breaking new generation of lithography for chip manufacturing systems. Our results provide deep insights into the collective and collaborative dimension of organizing R\&D in processes of technology development. Thereby, we contribute to a theory of technological paths that considers collective embedded agency and takes into account interorganizational forms for an understanding of the innovation dynamics in science-based industries such as semiconductor manufacturing.
\end{abstract}

\section{Corresponding author:}

Jörg Sydow, Freie Universität Berlin, Department of Management, Boltzmannstr. 20, D-I4I95 Berlin, Germany.

Email: joerg.sydow@fu-berlin.de 


\section{Keywords}

innovation, organizational fields, path creation, path dependence, R\&D consortia, semiconductor industry, structuration

\section{Introduction}

The initial success of a technology may turn into a state of persistence which strictly binds the further refinement of that very technology, sometimes even making it impossible to switch to an alternative. This phenomenon is known as 'path dependence' and is supported by a growing literature building largely on seminal work by David (1985) and Arthur (1989). Indeed, the dynamics of path dependence play an increasing role in technological innovation, particularly in the case of complex system technologies that strive for dominance (Suarez, 2004). More often than not, this development is related to institutional and/or organizational conditions that are themselves prone to path dependencies (e.g. North, 1990; Leonard-Barton, 1995; Hollingsworth, 2006). However, the classical theory of path dependence only provides limited explanations of how the phenomenon comes about, since it offers mainly an evolutionary view of paths. In particular, strategic collective agency does not play a major role in the explanation of the development of novel technologies in classical explanations of path dependence. Path processes, however, look very different once the efforts of agents involved in path constitution processes are accounted for (Garud \& Karnøe, 2001).

In this paper we present empirical evidence that challenges (once more) the basic assumption of classical path dependence theory (David, 2001) that the process of technology development is beyond the control of agents. Towards this end, we provide detailed insights into processes of collective organizing for path extension and creation as well as the strategic agency they both involve. Even from the social-constructivist ontology of paths (Garud \& Karnøe, 2001; Djelic \& Quack, 2007; Garud, Kumaraswamy, \& Karnøe, 2010) which we adopt, strategic agency is recursively related to self-reinforcing forces, which are characteristic of path dependence processes. This means our approach emphasizes the fact that agency and structure matter in this process and that collective agency is a variable force in technology development. In more detail, we are interested in how, in this process, collective agency makes use of organizational forms such as interorganizational networks. These are important extensions and refinements to recent contributions that have highlighted the role of agency (e.g. Garud \& Karnøe, 2001; Djelic \& Quack, 2007), but so far have neglected the active extension of an existing technological path and the role of governance in these very processes.

Based on an in-depth, longitudinal case study of the development of technological paths in the global semiconductor manufacturing industry, we will show how the extension of a path as well as the possible creation of an alternative path can be driven by endogenous agency, i.e. by industry actors who coordinate activities among themselves by referring to collective practices of technology development that enable and constrain their activities by certain structural and institutional conditions of the industry. Up until the 1980s, most transitions in semiconductor manufacturing technology were organized in-house by dominant players such as IBM. Since then, new technological challenges have been addressed increasingly in collaborative ventures such as R\&D consortia. This most important change in form, however, has not come naturally to the field, but is the result of a highly contested and contingent process which now governs the practices of innovation globally, not only in this industry.

In order to explain this industry-wide shift in the organizing practices of technology development, we draw on Giddens' (1984) theory of structuration and reconceptualize the concepts of path extension and path creation as two alternative modes of 'path constitution'. This means that we 
provide an integrated, multidimensional and multilevel analysis that, in contrast to other recent attempts (e.g. Thrane, Blaaberg, \& Møller, 2010), is not restricted to the cognitive dimension or just one level of analysis.

The paper proceeds as follows. In the next section, we revisit the notion of path dependence as derived from well-known debates in economics (David, 1985, 2001; Arthur, 1989; North, 1990) and historical institutionalism in political and social analysis (Thelen, 1999; Mahoney, 2000; Pierson, 2000). We contrast these prior conceptualizations to recent studies of 'path creation' (Garud \& Karnøe, 2001) and 'path generation' (Djelic \& Quack, 2007) and develop our own integrative and gradualist notion of 'path constitution' (Windeler, 2003) based on structuration theory. We then describe briefly the development of the 'organizational field' (DiMaggio \& Powell, 1983) of the global semiconductor industry as our research setting. After this, we elaborate on our research design and empirical methods. In the section which follows, we present our empirical findings. We show briefly how the industry changed to a more distributed and collective form of $\mathrm{R} \& \mathrm{D}$ and go into more detail concerning the differences in organizing collective agency in the cases of path creation and extension. Then we discuss our results with reference to earlier work on the theory of path dependence and path creation and conclude with the implications of our findings for researching technological paths and for organizing R\&D in consortia in relation to 'old' and 'new' paths.

\section{Embedded Agency in Technological Paths and Organizational Fields: From a Theory of Path Dependence to a Theory of Path Constitution}

The study of the development, diffusion and persistence of the QWERTY keyboard motivated David (1985) and, later, Arthur (1989) to develop their classical understanding of path dependence. According to these authors, the development of a technology is considered path-dependent when it is difficult, if not impossible, to diffuse a viable technological alternative due to increasing returns or other positive feedbacks. Also, this approach holds that one cannot predict in advance which technological option will eventually become a stable path, since path dependence is a non-ergodic process, i.e. one allowing for multiple equilibria, at least for a certain period of time. Because of positive feedback mechanisms combined with assumed individual profit-maximizing behaviours, certain potentially inefficient technological solutions may eventually become 'locked-in' (David, 1985).

However, by only 'looking in at the emergence of novelty' (Garud \& Karnøe, 2001, p. 8), this evolutionary perspective does not pay closer attention to the processes of how technological paths are brought about and/or reproduced in time-space. In line with Dosi's (1982) notion of a technological paradigm this seems important, however, since paths can be seen as the 'solution of selected technological problems, based upon selected principles derived from natural sciences and on selected material technologies' (p. 152; emphases in the original). We use structuration theory in order to analyse how actors apply different modes of collective agency in the creation, reproduction and extension of technological paths.

\section{Technological, Institutional and Organizational Path Dependencies}

Though originally confined to the development and diffusion of technologies, the notion of path dependence quickly travelled to comparative analyses of economic systems (North, 1990; Stark, 1992), regional economies (Grabher, 1993; Martin \& Sunley, 2006), political standards and social 
institutions (Thelen, 1999; Mahoney, 2000; Pierson, 2000; Streeck \& Thelen, 2005; Djelic \& Quack, 2007; Schneiberg, 2007) and, more recently, to the analysis of organizations and interorganizational relations (Sydow, Schreyögg, \& Koch, 2009; Gruber, 2010; van Driel \& Dolfsma, 2010; Koch, 2011; Valorinta, Schildt, \& Lamberg, 2011). All these studies stick to the core argument of canonical path dependence theory that technologies, institutions or organizations may become hyper-persistent because a small or bigger event triggers a process that is characterized by positive feedback and may eventually lead to a lock-in.

While the classical notion of path dependence contends that, within a locked-in path, actors' apparent choices are predetermined to essentially reproduce the given path, as compliance is rewarded and deviations from the path are not favourable, later contributions, from sociology and political sciences and most recently organization theory, challenged this assumption. They refined and adapted this concept in order to accommodate broader dynamics, endogenous as well as exogenous triggers of change, and collective agency.

\section{Path Dependence, Path Creation and Path Constitution}

Despite these important theoretical advances in the theory of path dependence, which include the rediscovery of the importance of structural elements internal to existing institutional systems for path generation (Schneiberg, 2007), current theorizing still lacks an adequate theoretical conceptualization of agency for a better understanding of the creation, maintenance and transformation of technological paths. Garud and Karnøe (2001), with their concept of "path creation', took an important step, re-emphasized later by Djelic and Quack (2007) with their notion of 'path generation'. Path creation, according to Garud and Karnøe, implies

that entrepreneurs may intentionally deviate from existing artefacts and relevance structures, fully aware they may create inefficiencies in the present, but also aware that such steps are required to create new futures. Such a process of mindful deviation lies at the heart of path creation. (Garud and Karnøe (2001, p. 6 , referring to Schumpeter, 1942)

In specifying their approach with regard to mindfulness, i.e. the need for continuous and creative engagement and accomplishment, and addressing the relationship between agency and structure, the authors also refer to structuration theory as a promising conceptual approach to understanding how technological paths are organized in practice (see Windeler, 2003). While Garud and Karnøe (2001) originally wished to substitute (intentional) path creation for (mostly emergent) path dependence, they now recognize the need to consider intentional action as much as unintentional consequences of this action, including the power of hidden self-reinforcing processes (Garud et al., 2010), an argument which perfectly fits the structurationist view of social constitution.

Giddens' (1984) theory of structuration offers a general theoretical model to analyse continuity and change in social processes in terms of their ongoing constitution. It also allows us to gradually differentiate between path creation and extension in terms of social practices. Path extension and path creation should not be seen as dualistic opposites, but as distinct yet related types within a plurality of technology development modes. Such a gradualistic understanding is supported by Giddens' theory and allows for knowledgeable agents to reflexively and recursively produce, reproduce and transform social practices, i.e. path extension as well as path creation. In this regard, structuration theory will help us see what collective agency looks like when it emerges under conditions which the individual actors, despite their knowledgeability and reflexivity, mostly cannot control. Thus, the concept of agency in structuration theory in general and in our concept of 
path constitution in particular fits an analysis at the organizational, network and field levels of issues surrounding technological innovations in a way that relates practices to paths.

\section{Path Constitution as Structuration in Fields}

Originally developed by Giddens (1984) as a social theory, the theory of structuration has actually been applied in organizational research to explain the relationship between structure and action at various levels (e.g. Barley \& Tolbert, 1997; Sydow \& Windeler, 1998; Li \& Berta, 2002; Pozzebon, 2004; Behrends, van Burg, \& van Raaj, 2011) as well as to explain the relation of technological and organizational change (Barley, 1986; Orlikowski, 1992; DeSanctis \& Poole, 2004; see Black, Carlile, \& Repenning, 2004 for a critical account). This research takes a decidedly social constructivist approach, accounts for mindful and yet embedded agency, emphasizes the recursive interplay of structure and agency in the constitution of social practices, and recommends analysing this interplay with regard not only to rule-related cognitive and normative isssues but also to resource-related issues of power and domination. In line with this, we propose that the structuration of technological paths at the level of organizational fields provides a valuable conceptual refinement of recent work on path dependence and path creation.

Via the theorem of the 'duality of structure' (Giddens, 1984, p. 25) in particular, structuration theory helps to clarify the role of economic and other social structures that - as rules and resourcesnot only restrain but also enable strategic agency. Likewise, path dependence (and technological paradigms, for that matter) and the underlying self-reinforcing mechanisms must be seen not only as constraining but also as enabling specific actions connected to a specific path or paradigm. Then again, strategic agency can be successfully directed towards shaping the path. Consequently, we trace 'knowledgeable agents' (Giddens, 1984, p. 30) and the differences in their practices of path creation and extension. In particular, we focus on the coordinated activities of collective actors (Hargrave \& Van de Ven, 2006) and the contested practices of making and continuing technological paths. This allows us to account for continuity and change in the transformations of shared practices for innovating complex technologies in a globally networked field.

\section{Research Setting and Methodology}

At first sight, our empirical field, the global semiconductor industry, looks like a classical case of technological path dependence. Early uses of optical lithography for semiconductor manufacturing date back to the late 1950s, when it was quickly adopted for the mass manufacture of transistors and the newly invented integrated circuits. Since the mid-1970s, optical lithography has been actively challenged as the dominant high volume manufacturing method by several alternatives. Mostly, these challenges came from other sources of exposure radiation, such as electrons, ions or $\mathrm{X}$-ray, going hand in hand with industry-wide predictions that optical manufacturing technology will reach a physical limit in shrinking feature sizes and therefore be unable to keep up the progression path set forth by 'Moore's law', which predicts that the number of transistors that can be placed on an integrated circuit doubles approximately every 18 months (Moore, 1965).

In general, semiconductor manufacturing is characterized by fast-paced technological change and a plurality of competing technological options for creating new, as well as for extending old, technological paths. Today, it is still unclear whether the industry will ever deviate from the current path of optical lithography. What makes semiconductor manufacturing an ideal setting for studying processes of path constitution is not only the fact that the present technology has long outlived its predicted lifecycle and that optical lithography has been unsuccessfully challenged by a broad 
range of technologically advanced alternative options. Rather, and in addition, industry experts agree that only one technological alternative for high-volume semiconductor manufacturing will prevail, with the consequence that the industry itself has organized the strategic quest for a new 'dominant design' (Abernathy, 1978; see also Anderson and Tushman, 1990; Suarez, 2004; Murmann \& Frenken, 2006) since the mid-1990s.

In contrast to the technological continuity of extending optical lithography, the forms of coordinating the development of promising technological alternatives have changed fundamentally. In the past, R\&D for semiconductors was controlled by single large, centrally positioned and vertically integrated corporations, such as IBM. Today, however, knowledge production and technological development activities in photonics are much more distributed, as in other sciencebased fields such as biotechnology (e.g. Powell, Koput, \& Smith-Doerr, 1996) or nanotechnology (e.g. Robinson, Rip, \& Mangematin, 2007). In these fields, R\&D consortia have become quite common. They are collective structures among formal equals that focus on a limited domain of activities such as carrying out $\mathrm{R} \& \mathrm{D}$, and that are typically dissolved after a pre-defined objective has been achieved (Doz, Olk, \& Ring, 2000; Sakakibara, 2002). The increase of R\&D consortia indicates that today new technologies are developed by sets of organizations in increasingly networked fields; i.e. in fields that are, on the one hand, characterized by networked R\&D consortia and, on the other hand, by networks along the value chain (e.g. Powell et al., 1996; Garud, Jain, \& Kumaraswamy, 2002; Powell \& Grodal, 2005; Hargrave \& Van de Ven, 2006).

This is also true of the field of semiconductor manufacturing technologies and its most prominent consortium SEMATECH, as a review of empirical studies shows (Grindley, Mowery, \& Silverman, 1994; Browning, Beyer, \& Shetler, 1995; Ham, Linden, \& Appleyard, 1998; Browning \& Shetler, 2000; Langlois, 2000; Linden, Mowery, \& Ham Ziedonis, 2000; Carayannis \& Alexander, 2004). Coming back to the question of how collective agency is organized in processes of path constitution, we will analyse how, and to what extent, technological change is pushed forward in collaborative ventures such as SEMATECH, EUV LLC or IMEC and how processes of path creation and extension may be distinguished. The starting point of our analysis was the persistence of optical lithography which, at first glance, appeared to be a locked-in technology. Then, during our research, we found that two strategies are being pursued in parallel in the semiconductor industry: one is dedicated to the creation of a new technological path and the second is oriented towards the extension of optical lithography itself. What is more, both were the results of strategic activities in the field and both were increasingly organized in collective $R \& D$ ventures. This gave rise to our central question of what roles the new organizational forms play for the reproduction of the dominant path and the creation of a new one.

\section{From Theory to Methodology}

Towards this end we apply a methodology that borrows the notion of constitution, the concept of the duality of structure in interaction, and the understanding of knowledgeability from structuration theory. In addition, we build on the literature on path dependence and path creation in order to address the constitution of a technological path in a particular field-something which Giddens did not specifically have in mind. We call this methodology 'path constitution analysis' or PCA for short, and apply it in an embedded case study approach (Yin, 2009) that adheres to recommendations by Garud et al. (2010) and makes use of interpretative methods (Lincoln \& Guba, 1985) for the analysis of processes of path extension and creation at the levels of organizations, interorganizational networks and/or organizational fields. Following up on early calls for a multilevel analysis of technological change (e.g. Tushman \& Rosenkopf, 1992), PCA seeks to identify aspects of 
contingency, self-reinforcement and lock-in at these levels. By considering technical feasibility and economic viability along the social dimensions of signification, legitimation and domination (Giddens, 1984), we follow a multidimensional approach.

Technological paths develop over time and are governed by distinct regimes that are complied with, reproduced or transformed by agents (Sydow et al., 2009). This makes PCA necessarily a longitudinal process analysis which looks at the embedded activities of individual and organizational agents in time-space (see also Poole \& Van de Ven, 1995; Black et al., 2004; Hargrave \& Van de Ven, 2006). In the case under consideration, we cover technological, institutional and organizational developments over the last 40 years, of which the last 20 years are analysed in greater depth with a very close look at processes of structuration since 2003, the start of our research project. The research design around our PCA method thus lends itself very well to the comparative longitudinal analysis of two (or more) competing technological alternatives over time.

We advance the idea of a gradual model of path constitution, in which we seek to overcome analytical dichotomies between either classic accounts of technological and institutional hyperstability on the one hand and those emphasizing unbound agency in processes of change on the other (cf. Windeler, 2003). Toward this end, we speak of multiple embedded agents gradually interrelating technologies, institutions and organizations over time, focusing in particular on the relations between organizations. Thereby, the constitutive properties of a path (triggering events, self-reinforcing mechanisms, possibility of a lock-in) have to be taken into account without conceptualizing them as disembedded mechanisms that deny agency (Pajunen, 2008).

\section{Data Collection and Analysis}

Our main sources of information are 96 semi-structured interviews conducted with 68 different persons from 2003 to 2010 (see Table 1 for details). Some of these persons were interviewed several times; on some occasions we talked to several persons in one interview. A total of 86 of the 96 interviews were in-depth interviews of about 60 to 90 minutes with specific sets of questions concerning the interviewee's area of expertise and addressing various issues within the project. The interviewees were development engineers, strategic technology executives and CEOs from chip manufacturers and system and component suppliers, as well as executives from leading R\&D consortia and government funding programmes. Out of the 68 interview partners, 14 were interviewed several times (including the panel, see below). These key informants are central actors in the field, who have a broad overview over global activities and enjoy a high reputation. They were also indispensable in cross-checking and validating our findings (Denzin, 1989; Kvale, 1995). By conducting interviews more or less continuously since 2003, we have been able to appreciate technology development as a process with new, continued and abandoned efforts on the part of actors involved in creating the artefacts and standards that might extend an established path or create a new one.

Of the 96 interviews, 11 were conducted in the form of a panel in which the same individuals were interviewed on an annual basis. The members of our panel, which comprised three or four selected representatives from manufacturers, suppliers and consortia, were interviewed in Europe and the United States in 2007, 2008 and 2009 (and one of them again in 2010). The annual panel enabled us to keep up to date with the fast speed of development in the industry. We asked the panel members to briefly judge the technological progress made in the last year and to comment on the latest developments shortly after the most important conferences in the field. The panel interviews were 30 minutes each (panel members are marked with an asterisk in Table 1). 
Table I. Field interviews

\begin{tabular}{llc}
\hline Type of organization & Region & Number of interviews \\
\hline Supplier & EU & $33^{*}$ \\
& US & 2 \\
Consortium & JP & 4 \\
& EU & 3 \\
Chip manufacturer & US & $21^{* *}$ \\
& JP & 4 \\
Research laboratory & EU & $7^{*}$ \\
& US & $5^{*}$ \\
Venture capitalists & JP & 1 \\
Agencies/Ministries & EU & 2 \\
Consultants & US & 2 \\
& JP & 1 \\
& EU & 4 \\
& US & 1 \\
\hline
\end{tabular}

*Number of panel members included

Of the 96 interviews, 54 were conducted in Europe (18 of which are follow-up interviews with key informants) and 31 in the US (including one follow-up), supplemented by 11 interviews in Japan. The difference in regions and organizational types displayed in Table 1 is largely due to the fact that many supplier companies are located in Europe and Japan, whereas the big chip manufacturers and relevant consortia are based in the US. The global division of labour visible in the interview list, therefore, is directly related to the actual regional separation of relevant suppliers and manufacturers.

This view from the inside was complemented by discussing our empirical findings and conceptual approach with seven selected academic scholars from the US, Europe and Japan who were familiar with the field. These discussions complemented our ideas on path constitution with further insights into the field. They also helped to compare our initial findings with other lines of research concerning the semiconductor industry.

The questions asked during the in-depth interviews targeted three levels of analysis, primarily the field level, but also the network level and sometimes even the level of single organizations. More macro aspects (e.g. national or supranational policies) were considered only when they had an influence on organizations, consortia or the field. In terms of content, the questions first gave us a better understanding of issues prevalent in the field. They addressed the organizational actors, the temporal organization of action, and the practices most central to path constitution. Following the duality of structure theorem (Giddens, 1984), they also focused systematically on the structuresi.e. rules and resources - enabling and constraining the practices, obviously emphasizing those that are related to organizing R\&D consortia aimed at shaping the technological path. In addition to obtaining general insights into the empirical field, this allowed the interviewees to elaborate their 
perspectives on the particularities of state-of-the-art technology development in the semiconductor industry, the irreversibility of technological options, and to point out relevant organizational issues to be addressed in our further data collection.

The interviews were transcribed verbatim and then coded, using both analytical and empirical categories. Individual coding was followed by group coding in order to refine the analysis. We used categories from the literature on path dependence and path creation (e.g. path-triggering event, self-reinforcing mechanism, lock-in) as well as from the theory of structuration (e.g. social practices, each with respect to rules and resources). We also identified relevant empirical categories and did in-vivo coding of novel insights concerning the practices of path constitution. For instance, hype cycles and learning curves are terms frequently used by the respondents to describe the dynamics of technological developments in their fields. By aligning our theoretical approach 'topdown' with our empirical findings 'bottom-up', we generated a research focus that enriches analytic generalizations with case specifics.

A source of information that provided us with additional opportunities to cross-check for validity was the content analysis of field documents, especially from the trade press, company reports and conference proceedings. Information about company mergers and acquisitions, shifts in strategic orientation, and industry comments on 'critical events' in the development of next generation lithography (NGL) since the mid-1990s was also collected, coded and related to each technological option pursued in the field. This enabled us to trace the industry's discourse on the increasingly networked R\&D structure over the last 10 to 15 years (see Table 2). The triangulation (Jick, 1979) of our findings by using different data sources and methods strengthens our comparison of the technological options and field structuration.

\section{Findings: Organizing R\&D Consortia for Extending or Creating a Technological Path}

At the time of our study, both path extension and creation have been followed actively and strategically, but in distinct ways, which we describe and explain below. Notably, the pathextending technology of liquid immersion lithography (LIL) has been promoted alongside the path-creating option of extreme ultraviolet lithography (EUVL). This happened partly under the umbrella of the same larger consortia and partly in more specific and restricted joint ventures and projects. Whereas LIL, as a technology in use, benefits from self-reinforcing connections between technologies and from established relationships between organizations in the field, such durable relations still have to be established for EUVL. This is a major difference and reflects somewhat different modes of collective agency. We will look at how new ties are created out of the existing rules and resources in the field. First, however, we will take a closer look at the role of R\&D consortia as 'locales' (Giddens, 1984) of collective agency for structuring the organizational field. As a legitimate social practice, collaborative R\&D forms the basis of both path extension and creation in this field. Also, both alternatives bring together nearly the same set of actors. Still, there are significant differences in the technical challenges between the two options, which resonated in the industry by labelling and treating LIL as a 'natural' extension and EUVL as a 'radical' alternative. To sketch the main practices of the actors involved in the processes of field structuration and technology development, we extract guiding sets of rules and resources from the complexity and diversity of rules and resources that agents refer to and eventually reproduce or transform in their activities. 
Table 2. Field documents

Trade press

Company publications

Conference proceedings
EE Times online, Silicon Strategies (published by United Business Media)

Electrical Design News, News Center and Business Center for Semiconductor Manufacturing (published by www.edn.com)

Heise online newsticker (German technology newschannnel, published by Heise Zeitschriften Verlag)

Optics \& Laser Europe (published by the Institute of Physics)

Optics.org weekly internet newsletter (published by the Institute of Physics)

Semiconductor Fabtech (published by www.fabtech.org)

Solid State Technology (published by PennWell)

Press releases and annual reports from the websites of all relevant companies and consortia

IBM Journal of Research and Development

Intel Technology Journal

ITRS roadmaps and roadmap updates

1995-today: Proceedings of SPIE, Microlithography

1996-today: Proceedings of SPIE, Emerging Lithographic Technologies

1997-200 I: SEMATECH: NGL Workshop papers and presentations

1999-2000: SEMATECH: International EUVL Workshop papers and presentations

200 I-today: SEMATECH (later with SELETE and EUVA): International

EUVL Symposium papers and presentations

200 I-today: SEMATECH: Workshops on EUVL masks, resists and

source papers and presentations

2002-2004: SEMATECH: Immersion Workshop papers and presentations

2004-today: SEMATECH, IMEC and SELETE: International Symposium on Immersion Lithography papers and presentations

2004-today: SEMATECH: Litho Forum (biannually) papers,

presentations and surveys

\section{$R \& D$ Consortia and the Structuration of the Organizational Field}

Irrespective of some variations in detail and a never-ending struggle over forms of coordination, the overall structure of the field of semiconductor tool manufacturing in general and of research on tools for manufacturing in particular has changed radically since the 1980s and early 1990s. As mentioned before, the change is from in-house development within large, vertically integrated corporations such as IBM (Browning et al., 1995; Mowery \& Rosenberg, 1998, pp. 124-135) and dedicated bilateral projects towards more networked activities, which are mediated through consortia and other collective structures (cf. Chuma, 2006). This trend was confirmed by our interviewees again and again. Today, the R\&D activities in this industry are mostly conducted in a distinct network mode of governance involving dozens of organizations (Sakakibara, 2002).

The significance of R\&D consortia and how they are coordinated relates in an important way to how far member organizations can control vertical supply networks. The development of a complex system technology like lithography requires all the components or sub-systems (e.g. source and 
optics) to fulfil the highest technical standards possible and they have to be mutually aligned to all other components with great precision:

The individual manufacturing steps are often mastered at an experimental rather than a scientific level and are difficult to replicate on different tools or in different facilities. Such complexity has historically required manufacturers to work closely with equipment suppliers to improve the performance of each tool. (Ham et al., 1998, p. 139)

As we indicated earlier, the collective efforts to monitor, organize, and control such complex technology developments did not come naturally to the industry (cf. Brown \& Linden, 2009). We will briefly sketch this out using SEMATECH, the most important locale for collective agency and the best researched consortium in this field by far (e.g. Browning et al., 1995; Ham et al., 1998; Browning \& Shetler, 2000), as an example.

SEMATECH was founded in 1987 by 14 high-tech companies (Intel, AMD, Motorola and IBM among them) representing at the time 85 percent of the US national capacity for semiconductor manufacturing, with funding from the US Department of Defense matching the member firms' contributions. Over the years, the consortium has expanded not only from US to global, but also from mainly horizontal to more vertical forms of collective action. Following the establishment of the Supplier Relations Action Council and the Partnering for Total Quality Program that set the stage for more collaborative efforts in 1989/90 (Browning \& Beyer, 1998), SEMATECH subsequently succeeded in coordinating joint quality improvements, equipment qualifications and research projects with component and sub-system suppliers in the different value chains for the much-needed equipment for manufacturing semiconductors. Yet this success was preceded by several failures. The first attempt to organize purely horizontal collaboration between device makers failed, as did another attempt to organize purely vertical collaboration. In the end, a mixed mode of horizontal and vertical collaboration seemed to minimize competitive issues (Carayannis $\&$ Alexander, 2004) and enable collective agency.

One first important insight of technology development in the semiconductor industry is that the changes in technological paths do not come about obscurely like the more or less continuous change of many social institutions (e.g. Streeck \& Thelen, 2005). Instead, these happen in institutionalized arenas focused on open competition, explicit discussion and purposeful selection. One important organizational change in this process was that the collaborating competitors first of all had to actively label joint R\&D activities as 'pre-competitive', so as to be able to join forces. Other forms of organizational and institutional change were also necessary, like changing anti-trust laws (LeClair, 2011) in order to permit cooperation between fierce competitors. As locales of cooperation, consortia serve as neutral ground for handling such delicate processes. Even if this looks somewhat like an unintended result of purposeful action, it is a basic achievement of the industry to construct and frame a decisive phase of technology development as 'pre-competitive'.

On the level of field structuration, the institutionalization of consortia involved changing the rules of signification and legitimation concerning accepted ways of sharing resources. Even though cooperation increased through consortia, it is still a very delicate matter in the field. A representative of SEMATECH noted this especially with respect to supplier companies:

Well, if it's their core knowledge or their competitive advantage, I don't think you're ever going to get IP rights or maybe even not get standby license based on their technical expertise. So unless you're funding them hopefully, 100 percent, you almost never get the background expert knowledge base on how people polish glass or what's the manufacturing recipe for the photo resist chemistry. (I-31: 20) 
Protecting valuable intellectual property thus constrains the shape of individual R\&D projects and influences the overall structure of collective agency. Together with the above description, the citation discloses an eminent, guiding set of rules and resources concerning the collaboration in R\&D consortia. First and foremost, it addresses a predominant rule of signification, i.e. labelling a field of activities as 'pre-competitive', allowing actors to join forces with even their closest competitors. In addition, it highlights that this rule is connected to an important rule of legitimation that allows the sanctioning of such collaborative endeavours as an appropriate procedure in the industry. Both rules are in turn supported by substantial funding and the organizing of meetings, which are used as powerful resources of domination by which actors are motivated to cooperate in the process of technology development. Together, these guiding sets of rules and resources characterize the collaborative $R \& D$ practices within consortia.

Today, the field of semiconductor manufacturing is characterized by numerous consortia; SEMATECH just remains the best-known one within the industry and beyond. In our case, the most prominent consortium besides SEMATECH was the Intel-led Extreme Ultraviolet Limited Liability Company (EUV LLC), a consortium which, as its name reveals, was dedicated to pushing EUV lithography (EUVL) - which has been the most promising NGL option in the field for over a decade (Linden et al., 2000, see also the 2010 ITRS update on www.itrs.net). Other cooperative R\&D efforts like PREVAIL (IBM and Nikon) were dedicated to promoting different options (in this case, electron projection lithography: EPL). Besides these dedicated consortia, there have been further R\&D activities coordinated within government-funded research programmes such as MEDEA+ in Europe or the industry consortium SELETE in Japan (Ham et al., 1998; Sigurdson, 2004). Suffice to say that since the late 1990s, all industry-wide NGL initiatives have been orchestrated within consortia and coordinated through global collective activities, mainly conferences and workshops (e.g. Möllering, 2010). As locales for collective agency, consortia enable both the more dyadic collective activities of extending the present LIL path and the more distributed and yet networked collective activities of creating the EUVL path.

\section{Fighting for the Existing Solution: Extending the Path of Optical Lithography}

The persistent and yet incremental evolution of present optical lithography over such a long time is neither self-evident nor completely path-dependent. True, the uncertainties of moving to any NGL option, together with the existence of well-established practices of technology development along the lithography path, led to 'a natural desire to extend the existing technology as long as possible' (Golda \& Philippi, 2007, p. 95). For this reason, as confirmed by all our interviewees, the industry fosters a conservative stance towards novel technologies along the lines of Tushman and Anderson's (1986) preference for 'competence-enhancing' rather than 'competence-destroying' technological breakthroughs. The collective actions are thus oriented towards incremental enhancements, which help the industry to collectively manoeuvre on an existing path. The 'new' is developed in extremely close relation to the 'old' - thus constituting at most a new technological trajectory within the current paradigm (Dosi, 1982), not an entirely new technological path. As we will see, in the particular case of LIL some 'paths not taken' (Schneiberg, 2007) are regaining attention, which is in sharp contrast to the creation of the EUVL path.

Viewed closely, optical lithography is less a case of emergent path persistence - as classical path dependence theory would have it - than one of mindful path extension, because 'this dominance of optical lithography in production is the result of a worldwide effort to improve optical exposure tools and resists' (Chiu \& Shaw, 1997, p. 3). This coordinated global effort becomes apparent through an increasing number of conferences and workshops in addition to a 
multitude of dyadic $R \& D$ relationships. What was true years ago still applies today with regard to current LIL developments. Our interviewees estimate that about 60 to 70 percent of their companies' overall $R \& D$ expenses are directed towards enhancing the current optical lithography systems.

The majority of the R\&D for LIL is conducted by companies individually or in closed bilateral projects between suppliers and customers, following the established individual/dyadic form of collective action prevalent in the field prior to the 1980s. Of course, these activities are embedded in field-wide sets of institutions, institutionalized practices and sets of rules and resources. For instance, the extreme financial and technological uncertainties over time created an industry-wide consensus which favours the incremental enhancement of optical lithography. A SEMATECH representative puts it like this:

It's not necessary that the overall solution is cheaper, but that the incremental cost is cheaper. So if I have to invest a certain amount, let's say it costs me a billion dollars to prove a new technology, but if I can prove that I can get 20 percent of the way there for 20 percent of the cost, I mean, to choose that 20 percent of the way, or maybe even if it costs me 30 percent of the cost to get 20 percent of the way there, it's still a lower risk, and I'm going to keep going on that incremental path because the steps are smaller and the amount of financial risk I have to take at any given point is better contained, and I think this is why the incumbent technologies are getting extended. (I-32: 18)

This statement reflects a guiding set of rules and resources which refer to the high value of past investments in tools and knowledge, quite literally a 'conservative' form of collective action. The rule of signification applied is that the smaller investment counts as less risky and better contained. At the same time, it discloses as a rule of legitimation that incremental investments of smaller amounts of money are considered the adequate way of dealing with the high uncertainties involved in the process of technology development in this industry. As we shall see, the connected resources of domination primarily concern exploiting the existing technological options and mobilizing the existing supply chain infrastructure. Consortia increasingly serve as locales of collective agency, where they allow for the bundling of both allocative and authoritative resources. This is true even though the coordinative effort for extending a path is much smaller than it is for creating a new one.

The general preference for smaller, cheaper and more predictable technological changes should not be equated with smooth and steady progress; because even in the case of extending optical lithography we find competing technological options. In the late 1990s, the industry singled out $157 \mathrm{~nm}$ lithography as a natural extension to $193 \mathrm{~nm}$ lithography and as a bridging technology until EUVL was ready. First, the development of $157 \mathrm{~nm}$ lithography ran smoothly along the conservative lines of extending the old. Then, early in the 2000s, $193 \mathrm{~nm}$ immersion lithography (LIL) appeared and the industry was faced with too many options, as a test facility representative pointed out:

Because this industry cannot support the development of multiple different technologies that would serve the same purpose, SEMATECH was asked to call a meeting and to try to get an overall opinion. And they called champions of $157 \mathrm{~nm}$ and also champions of EUV and champions of immersion lithography, and asked them all to basically try to defend their own technology. (I-15: 4)

The result of this coordinated decision-making process was that some major players, such as Intel, decided to opt out of $157 \mathrm{~nm}$. According to the industry rule, 'This industry cannot support the development of multiple different technologies that would serve the same purpose', this meant that the $157 \mathrm{~nm}$ alternative was made obsolete. Even though we see many collective efforts, the industry has not been able to make accurate predictions for extending optical lithography, and $157 \mathrm{~nm}$ lithography is often cited as a case in point: 
I can come up with a good example, which is the death of 157. Even though there were some purchase orders, that wasn't enough and there were some technical problems and the rate of convergence was not sufficient and then other options came up. ... And I think as a community, as the lithography community, the ability to predict the technology six years out has been precisely wrong 100 percent of the time. So that should say something. (I-32: 14)

Even though technological issues still needed to be solved, many industry experts considered 157 $\mathrm{nm}$ lithography technologically ready, whereas LIL was still in R\&D (and EUVL still far away). When, in May 2003, Intel publicly announced that it intended to discontinue $157 \mathrm{~nm}$ lithography, many companies did not follow this lead immediately. Their existing bilateral engagements were strong enough to uphold the feasibility and viability of the option. Yet within the year the industry's support for $157 \mathrm{~nm}$ ceased, while $193 \mathrm{~nm}$ LIL rapidly gained support. In this process, the industry's perception of $157 \mathrm{~nm}$ lithography changed from 'next best viable and feasible alternative' to 'too costly for the expected time of use'. Consequently $157 \mathrm{~nm}$ lithography was de-legitimized as a path extension option, development efforts stopped and purchase orders were cancelled. What followed was a reproduction of matching rules of economic legitimation and a quick withdrawal of resources, most of all in terms of money and manpower. We can see that even though $157 \mathrm{~nm}$ lithography was well advanced, it was not advanced enough and the development not robust enough to maintain its own momentum; $193 \mathrm{~nm}$ LIL seemed to offer an even more conservative route to extending optical lithography.

With LIL, the exposure radiation would continue to be $193 \mathrm{~nm}$, but it would be combined with a 100 -year-old optical principle. Put simply, immersion means that a drop of fluid (water or oil) is placed between the optical lens and the target, which leads to better image resolution due to the higher refractive index of the fluid compared to air. In 2001, the proof-of-principle research for LIL was conducted at the Rochester Institute of Technology, with some capital investment from chip manufacturers. Even though this technology is rather closely related to present optical lithography, this was not an obvious enhancement at the time. For instance, the maxim of keeping lenses and wafers absolutely clean and free from any disturbing substances was an important rule of signification for engineers and, therefore, served as a cognitive barrier against the idea of introducing a fluid, which would bring with it numerous sources of defects, e.g. bubbles or particles in the fluid, which may diffract or occlude the exposing light. In the history of enhancing lithographic technologies, the semiconductor industry has known many events by which technological taboos were broken and systems of meaning became transformed. For instance, some materials which were previously unthinkable later became important components for keeping up with Moore's Law, like the use of copper:

Many years ago, they said that nobody in a semiconductor fab would use a machine in which a silicon wafer somehow gets in contact with copper. Copper poisons the semiconductor process... . Today, the interconnects on the wafer are made of copper, because it has a better conductibility than aluminium. This is how times change. (I-18: 218)

Extending a path entails collectively overcoming technical barriers. This is also true for path creation, but the problems to be solved in path extension are much less demanding and most often concern only a few components. This means that many problems can be solved within the existing R\&D infrastructure and the commercialization of LIL was indeed taken up by supplier companies in bilateral projects. As our interviewees point out, the technology was so close to market introduction that they did not see the need to set up government funding programmes, but rather opted for a swift market introduction under their own control. However, these bilateral endeavours 
on the dominant path were backed up by a fine-grained adjustment of the overall technical, economic and social requirements in the field.

For commercializing shared manufacturing technologies, the industry uses collective test facilities such as IMEC in Belgium, SEMATEC North in the US, or SELETE in Japan. Because testing technological options for high-volume manufacturing requires immense investments and the so-called alpha tools are needed only for a very limited time, no single firm can afford to have their own. Even more importantly, these facilities are locales where component suppliers, system integrators and chip manufacturers meet, create the pre-competitive space described earlier, and exchange test results. In addition, they produce results on the same machines, which, in a way, are seen as more 'objective' than the results produced by companies on their own. The exchange of 'objective' results is of extreme strategic importance in an industry where economic success relies heavily on the functioning of a highly complex system technology with its extreme demands on the compatibility of its components.

In the field of semiconductor manufacturing, test facilities are crucial resources since they provide a more or less affordable gateway to new technologies for suppliers and manufacturers. They are not dedicated to one single technological option and therefore facilitate both path extension and creation by offering a locale for experimenting on prototype machines. In terms of field structuration, the test facilities help to reorganize the relations of the companies in a specific way. On the one hand they are very careful to offer a 'neutral space' for testing technologies. On the other hand, they are seen as highly political locales. From the perspective of Japanese tools suppliers, IMEC for instance is far from being neutral, but rather serves as a locale to promote ASML tools and effectively excludes Nikon and Canon. This controversy is implicitly reflected by a representative of IMEC. He pointed out with reference to the Japanese involvement in their immersion programme:

That only started with LIL, so in $157 \mathrm{~nm}$ we were talking to them but they were not convinced, it was not possible to convince them [to join us], but then again due to the good relation with ASML when it was decided basically by the industry to drop 157 and to go full speed ahead with immersion, we could get the agreement with ASML very quickly to get an early immersion scanner here, and it was clear that Nikon and Canon were not able to deliver that fast and basically [this] was then the starting point for a number of Japanese companies to become very interested in IMEC and get early access to the ASML technology here. (I-27)

We can see how the test facilities become locales for forging new interorganizational relationships and hence serve as important resources of domination in the field. We can also see that the rules of signification and legitimation changed as Japanese suppliers became interested in IMEC. The manifold instances of legitimate bilateral and networked cooperation found in the field should not hide the fact that the field is still characterized by fierce competition over technologies and between companies.

As we noted earlier, we conceive the extension of optical lithography to be strongly embedded in various sets of social practices that characterize the field. The actors in the field draw on existing practices of science and engineering, e.g. convening workshops and conferences, as much as those of business, e.g. setting up trade fairs, and they back them up with field rules referring to 'collaborative innovation strategies'. In addition, they relate to established practices of generating consensus in the industry, most notably the ITRS (see Schubert, 2007). By initiating a global consensus process on LIL and using industry-wide acknowledged locales for mutual monitoring, actors (re)produce a common understanding of where to go and how to act which is largely based on the existing path. In the field, progress has actually been monitored very carefully and critically. 
As claims of progress are typically exaggerated and problems are covered up, only highly competent actors in the field can accurately judge the overall status of the process. For this they rely heavily on informal information flows, e.g. aside from the official programme at consortia workshops and conferences (e.g. Möllering, 2010).

The extension of a path includes strategic, coordinated actions (with some unintended consequences) along a conflictual incremental process in which multiple technological, financial and political elements are interwoven over time. But the degree of collective R\&D in setting up conferences, workshops and consortia programmes is much smaller, as it takes less time and less financial and technological resources than path creation. Even though there are some important technical novelties in LIL, the actors not only changed some rules and resources, especially in the way that test facilities become locales of managing access to relevant technologies. To a relevant extent, they also stick to many of the existing rules and resources as a medium for path extension. Theses relate to the accepted mode of incremental enhancement through bilateral cooperation along the established supply chain as well as to the technical compatibilities, institutional conditions and learning curves of technologies in use. We will find some of the aspects of actively extending a technological path in the following example of path creation. In this case, however, not only the technical specifications between the existing technology and the technology in creation differ radically. In addition, many more actors, technologies, funds and networks need to be mobilized. In comparison, the collective agency for path extension was less distributed in terms of actors involved and more focused regarding the scope of technology development.

\section{Struggling for the New Solution: Creating a Path for Next Generation Lithography}

While $157 \mathrm{~nm}$ would have been and LIL definitively is a case of path extension, the EUVL option is a possible case of path creation. Even though all three options are lithographic solutions, their technical specifications differ radically. With EUVL, so many technological hurdles have to be taken at the same time that, when looking at the whole system, it resembles a radically different technology. When the technology was proposed as a possible successor to optical lithography, nearly all components (e.g. source, optics, mask and resist) were in early stages of R\&D and it was entirely unclear whether they could be aligned even at an experimental level. In comparison to 157 $\mathrm{nm}$ and LIL, EUVL could hardly draw on existing components, knowledge, standards, assessment criteria, or infrastructure. All of this had to be innovated along with the manufacturing technology itself. Therefore, the case of innovating EUVL involves, first and foremost, a larger amount of collective organizing in a contested terrain of higher complexity.

Setting and keeping the course for EUVL required significantly more than just technical feasibility, which is a highly complex achievement in its own right. In addition, each technological option for NGL has to be cost-effective for high-volume manufacturing - and the doubts in the industry regarding these two factors are magnified by the escalating development costs (hundreds of millions of dollars) and the long duration (significantly more than a decade). As the interviewees told us, one of the main aims of collaborative R\&D organized in and around consortia was to achieve, in the light of high technical and economic uncertainty, sustained industry-wide support for an NGL option such as EUVL. This is specific to path creation, since such support is already in place for extending an existing path of a well-tried technology. In the early phases of path creation, collective activities are thus mostly concerned with building up a resilient and powerful support infrastructure as well as new structures for signifying and legitimizing a novel technological solution. 
One of the first collaborative actions in order to set the course for EUVL happened when, in 1996-some years before $157 \mathrm{~nm}$ and LIL were even discussed-Intel invited all six tool manufacturers (ASML, Nikon and Canon plus the US firms SVGL, Ultratech and GCA still existing at that time) to discuss with them how to innovate EUVL. An Intel representative pointed out:

We showed them what we had in the internal lab that we want to commercialize down the road and we asked what they wanted to do with it. So we initiated this process essentially in 1996 that we had kept at a very low level of investment until then. (I-33)

One year later, Intel initiated the \$250 million public/private EUV LLC consortium with Motorola and AMD as a cooperative research and development agreement (CRADA) with three leading US laboratories: Sandia, Lawrence Livermore and E. O. Lawrence Berkeley National Laboratories. CRADAs were created in the Technology Transfer Act of 1986 in order to increase US industrial competitiveness and were commonly used in the mid-1990s. As one of the 963 Department of Energy CRADAs initiated in 1997, the EUV LLC was unusually large and had a unique membership structure, with the device manufacturers investing heavily into a technology they only use, but do not produce themselves (Mowery, 2003). While the instrument of CRADAs was established, the whole set-up of EUV LLC was completely new, even sparking a congressional investigation concerning possible harm to US industry and security interests.

The consortium was dedicated to pushing EUVL (Linden et al., 2000), first by delivering a proof-of-principle for its technical feasibility by the year 2000 (the year originally aimed at), and second by establishing early R\&D relations with relevant suppliers such as ASML, Nikon and Canon. Third, EUVL was pushed further by the announcement of the leading chip manufacturers' interest in this option to the whole industry, as a component supplier pointed out:

It was the aim of this consortium to demonstrate the feasibility of EUVL. This was particularly important because of the complexity of the technology. But it not only gave evidence of the technical feasibility but also created enthusiasm, which was its aim, too. (I-6)

We can see here that the formation of the consortium goes well beyond mere technical and economic concerns. Especially for the device makers, as well as for ASML, the only non-Japanese tool manufacturer, the consortium was the primary locale for mobilizing collective efforts to legitimately deviate from the established technological path. In addition, lead actors such as Intel reflexively used their immense material and non-material resources to coordinate the activities and relations of the consortium members. For these very reasons we consider this to be a case of active path creation - rather than a case of passive path emergence which, as classical path dependence theory would have postulated, is triggered by a 'small event' and takes place largely behind the backs of actors. In contrast to path extension, we can also see that the common practices of R\&D were drastically altered in order to establish the EUV LLC, which in turn signalled the importance of EUVL to the whole industry.

EUVL was actively coined as the prime successor technology to optical lithography and collectively signified as the solution favoured by the members of the EUV LLC. This rather 'big event', in turn, legitimized the use of resources to sustain the endeavour to deliver the proof-ofprinciple for EUVL's technical feasibility, first of all for the members of the consortium. Moreover, this 'event', or rather the practices initiated by the event and referring to it, further institutionalized sets of rules and resources which not only demanded one shared technological solution for the whole industry but addressed EUVL as the solution being sought. The signalling of major 
companies to commit to this option motivated and legitimized other companies such as IBM and Infineon to follow suit by joining the EUV LLC. At the same time some of them reduced their support for other NGL options - as IBM did with EPL and Infineon with IPL. ${ }^{1}$ Of course, EULV was also pursued outside the US. For instance, ASML in the Netherlands, Carl Zeiss in Germany and Oxford Instruments in the United Kingdom were partners in the European EUVL programme EUCLIDES, while the Japanese government-funded ASET programme brought together companies such as Hitachi, Fujitsu, Sharp, Toshiba, NEC, Matsushita, Sony and Nikon. Thus the first instance of path creation was to draw together a network of supporters around an idea rather than around a more or less proven solution. All early collective efforts were directed at establishing this idea as a potent and legitimate successor technology.

The cooperative R\&D ventures show how the industry seeks to align actors and technologies, often with a regional focus. All of these programmes are aimed at creating stable and dedicated sets of actor constellations - a first step to generate momentum (cf. Hughes, 1983, pp. 140-174) - and even some form of self-reinforcement, because the commitment of key actors induces the commitment of more actors. We will explore the EUV LLC a little further, because it represents an unusually big event to push EUVL by bringing together the main industry players, even redirecting them from other options, thus building a powerful basis for distributed collective agency.

At the early stage of development, a new industry-wide rule of signification became apparent in the coining of names. NGL by name is supposed to appear as a natural successor to the current generation of lithographic technologies. At the same time, NGL conveys the idea of novelty since the next generation is also a new generation. The creation of the new technological path must technically and semantically connect to and differ from the established path. This delicate balance is at the heart of the collective agency generated early on in the dedicated EUVL consortia. There are some noteworthy particularities of EUVL: technically, it is closely related to X-ray lithography, a failed NGL option mainly pushed by IBM since the late 1970s and 1980s. In order to avoid linking EUVL semantically to the failed X-ray option, the name extreme ultraviolet lithography was chosen. Since deep ultraviolet radiation is the basis of current optical lithography, the adjective 'extreme' creates a semantic path extension while technically setting up the creation of a new path. This tension is still present in the conflicting rules of legitimation that actors refer to in our interviews: opponents refer to EUVL as 'basically X-ray' and thereby invoke the consensual criticism of the failed option. Proponents of EUVL, while admitting to radical changes, frame it as the 'natural successor' to optical lithography and the least radical solution among the NGL alternatives. As such, EUVL is collectively sanctioned as the legitimate follow-up technology and the solution that is least radical and critical and thus the safest and resource-saving option. At least semantically, the proponents try to connect EUVL to the well-tried technology of the established path and the know-how of the technology in use, drawing on the self-reinforcing learning curves of classic optical lithography. All of these collective activities only serve to create shared frames of orientation towards a highly uncertain technological option. In addition, the actors used the EUV LLC to pool authoritative and allocative resources.

The suppliers in the field monitored, rationalized and adjusted their activities strategically to the endeavours of the EUV LLC. This has its rationale in the fact that the members of the EUV LLC represent important device makers in the field, most notably Intel as the eminent market leader and potentially largest customer. Together, these activities initiated a growing support for a highly promising technological option. The trade press around the year 2000 confirms this picture. Yet, it was not only the rhetoric in press releases but the actual backing of these expectations with significant amounts of money which sustained the momentum: 
If this technology doesn't work, we're going to be out on the order of $\$ 250$ million. On the other hand, if it works, what we want to do is recover our investment. But more importantly, what we want is access to the tools prior to our competitors who didn't take that risk. (Sander H. Wilson of Intel, cited in Linden et al., 2000, p. 103)

In order to secure this strategic advantage, an increasing number of firms subscribed to this technology. And there are some more reasons. Apart from having become a legitimate form and locale of state-of-the-art R\&D (see Hagedoorn, 2002, for evidence of the spread of alliances in this area), membership in $R \& D$ consortia is seen as enabling the companies to time their investments more precisely with regard to other companies' investments. In addition, membership in consortia became recognized as a way to tie smaller companies with a limited budget to one technological option, thereby creating durable commitments (Ghemawat, 1991). This includes the fact that strategic membership of supplier companies in selected consortia projects can effectively block the access of competing companies to the same R\&D process. Last but not least, with the initiation of the EUV LLC, Intel sought to generate technology-related intellectual property, so that no company outside the consortium would be able to lead or block R\&D for EUVL once the technology became more mature - a rather sophisticated way of resource control, augmented in this case by sets of relationships among the members of EUVL LLC which are also the major industry players.

After delivering the proof-of-principle, EUV LLC officially ended in 2003, but the coordinated efforts did not. SEMATECH, for instance, organized 9 EUVL symposia from 2002 to 2010, 15 EUVL source workshops from 2001 to 2009, and 13 EUVL mask workshops from 2002 to 2008. In this sense, EUV LLC was the indispensable kick-off to a much larger collective research effort. In short, path creation includes strategically coordinated activities of powerful agents and the formation of increasingly irreversible ties between organizations with the expectation of actually creating some form of self-reinforcing process towards the realization of a particular technology in the future. The enormous efforts directed at creating a new technological path at the same time transformed the way collective agency was organized. Even though collaboration existed before, the collective push for NGL alternatives led to a new quality of networked R\&D in semiconductor manufacturing. Figure 1 summarizes the most important sets of rules and resources guiding the practices of collaborative R\&D in consortia as well as of collaborative path extension and creation. Path extension and path creation are pictured as specific configurations of the guiding rules and resources which govern collaborative $\mathrm{R} \& \mathrm{D}$ in consortia. Whereas path extension builds mainly on consensus and follows a conservative mindset, path creation concerns the organization of conflict and entails a more disruptive way of thinking. As actors engage in path extension and path creation activities, this of course changes the overall shape of collaborative R\&D as we have shown above.

\section{Comparing Path Extension and Path Creation: Commonalities and Contrasts}

As the study of both LIL and EUVL suggests, path extension and path creation both involve carefully organized collective agency and are closely linked to the prolongation, reconfiguration or creation of interorganizational relations within the field. Nearly the same actors are involved in path extension and creation, acting in the same organizational field and sharing a common history in semiconductor manufacturing. For that reason, we would not expect totally different practices of extending or creating a path. But there are nevertheless important differences in development of the technology itself, the amount and mode of collective agency, and the usage of organizational forms for coordinating it. 


\begin{tabular}{|l|l|}
\hline \multicolumn{2}{|c|}{ Collaborative R\&D in consortia } \\
\hline $\begin{array}{l}\text { Rule of } \\
\text { signification }\end{array}$ & $\begin{array}{l}\text { Labelling a field of activities as 'pre- } \\
\text { competitive' to join forces with even } \\
\text { closest competitors }\end{array}$ \\
\hline $\begin{array}{l}\text { Resources of } \\
\text { domination }\end{array}$ & $\begin{array}{l}\text { Motivating actors to cooperate in the } \\
\text { process of collaborative technology } \\
\text { development by substantial funding and } \\
\text { organizing sets of meetings }\end{array}$ \\
\hline $\begin{array}{l}\text { Rule of } \\
\text { legitimation }\end{array}$ & $\begin{array}{l}\text { Claiming these endeavours as necessary } \\
\text { and appropriate in processes of } \\
\text { collaborative technology development }\end{array}$ \\
\hline
\end{tabular}

\begin{tabular}{|l|l|}
\hline \multicolumn{2}{|c|}{ Collaborative path extension } \\
\hline $\begin{array}{l}\text { Rule of } \\
\text { signification }\end{array}$ & $\begin{array}{l}\text { Labelling smaller investments as } \\
\text { 'less risky and better contained'; } \\
\text { reassessing known problems }\end{array}$ \\
\hline $\begin{array}{l}\text { Resources } \\
\text { of } \\
\text { domination }\end{array}$ & $\begin{array}{l}\text { Exploiting existing technological } \\
\text { know-how and drawing on the } \\
\text { current supply chain infrastructure }\end{array}$ \\
\hline $\begin{array}{l}\text { Rule of } \\
\text { legitimation }\end{array}$ & $\begin{array}{l}\text { Consensually sanctioning incremental } \\
\text { investments as the adequate way of } \\
\text { dealing with the high uncertainties } \\
\text { involved in the process of technology } \\
\text { development in this industry }\end{array}$ \\
\hline
\end{tabular}

\begin{tabular}{|l|l|}
\hline \multicolumn{2}{|c|}{ Collaborative path extension } \\
\hline $\begin{array}{l}\text { Rule of } \\
\text { signification }\end{array}$ & $\begin{array}{l}\text { Labelling a technological option as an } \\
\text { 'extreme' but also 'natural' successor to } \\
\text { the existing technology; exploring the } \\
\text { unknown }\end{array}$ \\
\hline $\begin{array}{l}\text { Resources of } \\
\text { domination }\end{array}$ & $\begin{array}{l}\text { Mobilizing new sets of actors and } \\
\text { technologies to reach a proof of principle } \\
\text { and coordinate further cooperation }\end{array}$ \\
\hline $\begin{array}{l}\text { Rule of } \\
\text { legitimation }\end{array}$ & $\begin{array}{l}\text { Collectively deviating from the } \\
\text { existing path while organizing } \\
\text { competing ways of sanctioning a } \\
\text { technological option as appropriate }\end{array}$ \\
\hline
\end{tabular}

Figure I. Structuration of technology development: guiding sets of rules and resources

In the case of path extension, many of the components are available or have to undergo only minor adjustments. Because the technology is considered to be close to the market, companies prefer bilateral projects to protect their intellectual property. In the case of path creation, most of the technological issues have not yet been resolved, creating a need for basic research that is not directly connected to competitive issues and calls for a more distributed and more extensive collective effort. In particular, it should not be underestimated that LIL builds on an existing supply chain infrastructure - something which has to be more or less created from scratch for EUVL. Even though most of the companies can already be found in the organizational field, their relations in the future supply chains of EUVL still have to be created - and that was one of the purposes of EUV LLC. In terms of structuration theory, path extension is mainly concerned with controlling the resources for making incremental enhancements. Path creation, at least in the early phases, is much more a collective effort to develop new ideas geared towards fundamental change and to transform accordingly the rules of signification and legitimation as well as the resources of domination.

R\&D consortia such as SEMATECH, EUV LLC or IMEC play a decisive role in organizing the collaborative processes, for path extension as well as for path creation. Despite this basic similarity, there are obvious differences in the timing, framing and status of technological development as well as in the coordinative efforts and the constitution of the technological path. Table 3 provides an overview of our findings in these respects. The number of plusses indicates the relevance of each element for either path extension or path creation. While we find roughly the same coordination efforts and self-reinforcing mechanisms at work, their respective significance differs in path extension and path creation. It was only for government funding and dedicated consortia in the 
Table 3. Comparing path extension and path creation

\begin{tabular}{|c|c|c|}
\hline & Path extension (LIL) & Path creation (EUVL) \\
\hline \multicolumn{3}{|l|}{ Commonalities } \\
\hline Persistent technological development & +++ & +++ \\
\hline General, non-dedicated consortia & +++ & +++ \\
\hline Collective testing facilities & +++ & +++ \\
\hline Inter-organizational relations & +++ (dyads) & +++ (networks) \\
\hline \multicolumn{3}{|l|}{ Contrasts } \\
\hline Proof of principle & 2001 & 2000 \\
\hline Ready for fabrication & 2005 & expected $2012-2015$ \\
\hline Time frame & relatively short & relatively long \\
\hline Costs & relatively low & relatively high \\
\hline Technological obstacles/uncertainty & high & extremely high \\
\hline $\begin{array}{l}\text { Degree of technological complementarity/ } \\
\text { inter-dependence }\end{array}$ & high & extremely high \\
\hline Technological status during development & in use & experimental \\
\hline Semantic framing & $\begin{array}{l}\text { minor change to existing } \\
\text { technology, paths not } \\
\text { (yet) taken matter }\end{array}$ & $\begin{array}{l}\text { successor to existing } \\
\text { technology, focus on } \\
\text { generating entirely new ideas }\end{array}$ \\
\hline \multicolumn{3}{|l|}{ Coordinated efforts } \\
\hline Government funding & 0 & ++ \\
\hline Dedicated consortia & 0 & +++ \\
\hline Bilateral projects & +++ & + \\
\hline $\begin{array}{l}\text { Conferences etc. (often organized by } \\
\text { SEMATECH) }\end{array}$ & + & +++ \\
\hline \multicolumn{3}{|l|}{ Self-reinforcing aspects } \\
\hline Know-how on existing technology & +++ & + \\
\hline Technological compatibility & +++ & + \\
\hline Established partnerships & +++ & ++ \\
\hline
\end{tabular}

+indicates level of importance $(0=$ no importance; $+++=$ highly important $)$

case of path extension that we found no empirical evidence, which is indicated by the number 0 in the table. By rating the importance of the categories based on our empirical material, we employ an abstract classification just for the purpose of creating a concise overview.

By comparing LIL and EUVL, we can sketch out the different forms of path constitution in the cases of path extension and creation. The general difference between path extension and path creation is the incremental enhancement of a technology in use compared with innovating a radical alternative that barely works in laboratory conditions. Although the distinction of incremental vs. radical innovation, if useful at all, clearly depends on the perspective taken, all actors in the field of semiconductor manufacturing seem to share the view that LIL is much less radically new than EUVL. This is hardly surprising, since all actors involved know that the timeframes for developing EUVL are much longer, the costs much higher and the technological obstacles far more demanding. Exact figures concerning economic costs are hard to obtain, but the interviews and the publicly available data as well as the process of technology development itself support this interpretation. In comparison, the amount of collective action involved in path extension is significantly smaller: 
Table 4. Path extension and path creation: modes of collective agency

\begin{tabular}{|c|c|c|}
\hline Focus & Path extension (LIL) & Path creation (EUVL) \\
\hline $\begin{array}{l}\text { Main target } \\
\text { of collective } \\
\text { agency }\end{array}$ & $\begin{array}{l}\text { Maintain a set of supporters around a } \\
\text { more or less proven solution as well as } \\
\text { the established relations among them }\end{array}$ & $\begin{array}{l}\text { Organize a new set of supporters around } \\
\text { an idea and establish durable relations } \\
\text { among believers in the idea }\end{array}$ \\
\hline $\begin{array}{l}\text { Main locales } \\
\text { of collective } \\
\text { agency }\end{array}$ & $\begin{array}{l}\text { Multitude of dyadic } R \& D \text { relationships } \\
\text { between suppliers and manufacturers, } \\
\text { backed up by general consortia }\end{array}$ & $\begin{array}{l}\text { Sets of interrelated R\&D consortia (general } \\
\text { and option specific) between suppliers, } \\
\text { manufacturers and research institutes }\end{array}$ \\
\hline $\begin{array}{l}\text { Main issues } \\
\text { of collective } \\
\text { agency }\end{array}$ & $\begin{array}{l}\text { Technical feasibility of one (or a small } \\
\text { number of) component(s) of an } \\
\text { established technology with a calculable } \\
\text { time and cost frame - and calculable } \\
\text { technological risks }\end{array}$ & $\begin{array}{l}\text { Technical and economic feasibility of a } \\
\text { set of components of a technology to be } \\
\text { established with a fundamentally uncertain } \\
\text { time and costs frame - and technical } \\
\text { obstacles difficult to overcome }\end{array}$ \\
\hline $\begin{array}{l}\text { Main area of } \\
\text { collective R\&D }\end{array}$ & $\begin{array}{l}\text { Near to production; close to } \\
\text { competition }\end{array}$ & $\begin{array}{l}\text { (Near to) fundamental research; pre- } \\
\text { competitive }\end{array}$ \\
\hline $\begin{array}{l}\text { Main change in } \\
\text { structure }\end{array}$ & $\begin{array}{l}\text { Modified reproduction of an existing set } \\
\text { of rules and resources related to the } \\
\text { established technology }\end{array}$ & $\begin{array}{l}\text { Creation of a new set of rules and } \\
\text { resources related to the technology to be } \\
\text { established }\end{array}$ \\
\hline
\end{tabular}

there are no dedicated consortia, no government funding of collaborative R\&D, fewer conferences and workshops, significantly shorter development cycles, and less networked R\&D even within the consortia (see Table 4). The mode of collective agency is also different. In the case of EUVL the agents put significantly more emphasis on the generation of (radically) new ideas, while in the case of LIL the implementation of relatively well-known insights is the main concern.

With regard to the coordinated efforts in the field, the most striking difference is the absence of dedicated consortia and government funding from the path extension alternative. As the interviews have shown, the initiation of EUV LLC as the first large-scale consortium exclusively dedicated to developing EUVL should not be seen as a random 'small event' (Arthur, 1989) which may become significant only in hindsight, but as a purposefully staged 'big' event. For EUVL, the most important work to bring the technology from the laboratory to the factory is done in dedicated consortia, whereas for LIL, this is done in bilateral projects. These bilateral projects, however, are embedded in a networked organizational field, flanked among others by seven SEMATECH symposia on immersion lithography from 2004 to 2010 . The more uncertain and pre-competitive the technology is, the more interorganizational collaboration seems to be sought for technology development. This is more likely to be the case in processes of path creation than path extension. Especially at the early stages of path creation, government funding and conferences in support of distributed collective efforts are significantly more important than for path extension.

The self-reinforcing aspects of path extension, but increasingly also of path creation, are the most relevant features of the way the technological path develops (Sydow et al., 2009). However, analysis of these self-reinforcing aspects requires that attention be paid to the activities of knowledgeable and powerful agents, including the ways in which they coordinate their activities in time-space and, even more importantly, how their practices produce and reproduce sets of rules and resources that relate to positive feedbacks, i.e. trigger or maintain or abandon such processes. Thereby, it is very difficult to independently rate know-how, compatibility and partnerships or to assign priority to any one aspect over the others. What we can see with EUVL is that - especially in situations of great uncertainty-established partnerships seem to be of more importance than 
know-how or compatibility. In a sense, the actors in the field inadvertently created the organizational path of collective R\&D by trying to extend and create new technological paths. As a result of this process, interorganizational networks - including the links between organizations within consortia, the links between consortia, and along the supply chain - and especially the networks resulting from close collaboration at the two global testing facilities (IMEC in Belgium and Albany Nanotech in the US) - became central locales for technological innovation (for similar findings in the biotech industry, see Powell et al., 1996). In an interesting dynamic of events, it is actually the early collective efforts of innovating NGL in the 1990s that paved the way organizationally for more collective efforts at extending optical lithography.

While the technological paths are still heavily debated in the field, the path of collective R\&D is now taken for granted, i.e. institutionalized in the field. Interestingly, the development of this organizational path was triggered significantly by external shocks (loss of world market share in the US and the financial crisis in Japan) which, however, agents first had to become aware of and, in addition, had to consider as opportunities for strategically reorganizing their activities. On the other hand, the process of collectively extending and creating technological paths is predominantly initiated and sustained by endogenous factors, most notably the large investments made to fulfil the prophecies of Moore's law.

Even though the R\&D networks have become so widespread and accepted in the industry, the practices of coordinating fierce competitors to engage in collaborative ventures with each other remains a matter of delicately tailoring each consortium and programme to the needs of its participants. Creating a technological path by means of different $R \& D$ consortia and programmes means skilfully manoeuvring within the legitimate boundaries of the field, adapting to existing as well as emerging organizational and institutional constraints, while at the same time creating durable relations between the future producers and customers of this technology. Network forms of governance, despite their collaborative flavour, do not reduce the struggle for new technologies and only soften the individual technological uncertainties and economic risks; they may also foster false hopes and the illusion of control. But as consortia become taken for granted in the field, we have to discuss how this figures in the process of technology development specifically and the constitution of technological paths in general in order to include the role of networks into a theory of path constitution.

\section{Discussion: Path Constitution in Networked Fields}

Our path constitution analysis of the NGL field originated from the economic theory of path dependence (David, 1985; Arthur, 1989) but modified this theoretical device significantly on the basis of more recent contributions to the debate (e.g. Pierson, 2000; Garud \& Karnøe, 2001; Windeler, 2003; Djelic \& Quack, 2007; Sydow et al., 2009; Garud et al., 2010), not least by using structuration theory in order to account for embedded collective agency. To some extent, our contribution reiterates the well-established insight that, in order to understand technology development, one has to look at processes of organizing innovation in collective settings in general and what is often called 'innovation networks' in particular (e.g. Freeman, 1991; Powell et al., 1996; Powell \& Grodal, 2005; Dhanaraj \& Parkhe, 2006; Hargrave \& Van de Ven, 2006). However, we go further with our explicit focus on how organizational agents, enacting structures of the organization, the network and/or the field, mindfully create and extend a technological path that is triggered by some event, that is driven by self-reinforcing processes (re)produced at least in part by collectives of powerful actors and, at least potentially, that leads into a lock-in. 
Our study points to the importance of different amounts of collective agency and different types of relationships for the creation and extension of a technological path: complex networks in the case of the R\&D consortia that promote EUVL, and simpler dyads embedded in networked organizational fields in the case of the project-based collaboration that dominates LIL. These interorganizational relationships are not only a medium, but also a result of mindfully creating and extending the technological path, and hence closely related to agency (Garud, Hardy, \& Maguire, 2007). Beyond this relational embeddedness, individual as much as collective agency, focused more on the generation of entirely new ideas in the case of EUVL and more on the implementation of relatively well-known solutions in the LIL case, is embedded in structures of signification, legitimation and domination that are enacted, reproduced and eventually transformed in processes of path constitution at several levels of analysis. Compared to path creation, extending a path is incorporated much more into the existing structures of the field and therefore requires significantly less mindful deviation from these structures. But as path extension becomes more costly and complicated, we also find similarities with path creation.

Most importantly, and differing from the seminal works by David and Arthur, we have demonstrated that technological paths are not necessarily an emergent phenomenon, at least when 'emergent' means that the results of social processes are beyond the control of agents. Rather, we have shown how paths can be created and extended by powerful actors, especially in networked organizational fields, using practices that address the self-reinforcing mechanisms underlying path dependence and, in case of success, path creation. Further to institutionalist studies in political and social analysis (e.g. Thelen, 1999; Mahoney, 2000; Pierson, 2000; Schneiberg, 2007) as well as more recent investigations of organizational path dependence (e.g. Sydow et al., 2009; Gruber, 2010; Koch, 2011; Valorinta et al., 2011), our research thus emphasizes the strategic agency involved in both path creation and path extension.

Our research is also in line with the theory of path creation or generation as put forward by Garud and Karnøe (2001) in the field of technology and Djelic and Quack (2007) in the institutional realm, respectively. However, we underline the importance of collective agency not only for the initial creation but also for the maintenance or breaking of a path. In addition, our structurationist understanding of path constitution deviates from these two approaches in three other respects: first, by emphasizing the importance of self-reinforcing processes and showing how organizational agents can not only use them passively but also influence them actively (however, see also Garud et al., 2010; Sydow, Lerch, \& Staber, 2010); second, by taking a more explicitly multilevel approach to path constitution, and third, by adopting a gradualist understanding of path constitution (see also Windeler, 2003; Meyer \& Schubert, 2007). Nevertheless, even though the actors in the cases under investigation actively strive for a dominant design and intentionally seek to benefit from selfreinforcing processes (such as learning curves or complementarity effects), they do not always have an explicit - not to mention complete - understanding of the processes of path constitution, nor are they in control of these processes, - at least not completely. Despite this qualification, reflexivity is strongly present in cases of path creation and path extension where actors engage in organizing R\&D consortia and the other types of networks identified in the field of lithography. These networks seem not only to support organizing processes, but - as social systems - are themselves outcomes of organizing, conceived here as reflexive structuration at the field- and network-levels (Giddens, 1984; Sydow \& Windeler, 1998; Windeler \& Sydow, 2001; Behrends et al., 2011).

In particular, R\&D consortia seem to have been intentionally and reflexively 'engineered' (Doz et al., 2000) in this field. Once created, as (network) structures in the field they support the structuring process (Giddens, 1984; Black et al., 2004). This comes as no surprise in an industry in which collectively organized path constitution is decisive and the organizational field itself is subject to 
strategic influences and reflexive structuration (see also Leblebici, Salancik, Copay, \& King, 1991; Hoffman, 1999; Greenwood \& Suddaby, 2006; though all with respect to other industries), driven by only a very small number of globally relevant end producers and system suppliers and integrators. Nevertheless, this is extremely important for an understanding of the interplay of collective agency on the one hand and network and field structures (and structuring) on the other.

\section{Conclusions and Directions}

This study, which is set in the semiconductor tool manufacturing industry, enhances our understanding of the mindful and gradual constitution of technological paths, i.e. of technologies that are actively kept (or intended to get) on a self-reinforcing track. Most of all, the paper contributes to the literature on path dependence and path creation by developing a broader and gradualist concept of path constitution that is based on structuration theory (Garud \& Karnøe, 2001; Garud et al., 2002, 2010; Windeler, 2003; Sydow et al., 2009, 2010), but helps to bridge 'thick' case description on the one hand and formal social theory on the other by studying the middle ground in a time-sensitive manner (cf. Black et al., 2004). The concept of path constitution in this regard accounts for the recursive interplay of socially embedded strategic agency and endogenous change and of 'external' events, unintended consequences and unacknowledged conditions of action. Thus, it stays sensitive not only to strategic agency based upon, and the intentional reproduction or transformation of, social structures, but also to emergent properties of technological, institutional and organizational paths,including their often subtle interplay. Hence our research demonstrates the value of analysing both the evolutionary forces highlighted by classical path dependence theory and the importance of agency, in particular collective agency, involved in both extending and creating paths by purposefully influencing self-reinforcing processes. If anything, this formulation enables us to distinguish between lock-in situations that are deliberately sustained and those that persist despite strong resistance and deviance on the actors' part.

Although this paper is based on rich data gathered over many years of field research, it remains exploratory in terms of the intended contributions to future conceptual and empirical organization research on technological paths. In particular, the empirical findings would profit from more insights into the often subtle processes within R\&D consortia that are likely to be plagued by conflicts and tensions to a larger degree than is reflected in our data (see also Van de Ven \& Garud, 1993; Hargrave \& Van de Ven, 2006). This would most likely require ethnographic research methods to complement the data we gathered from dozens of interviews and a broad range of secondary sources. For it may well be that in the face of extreme uncertainty, mutual interdependence and fierce competition, conflicts are suppressed by the need for consensus and hence are very difficult to detect. In addition, the findings of our study need to be contrasted with cases of more emergent technological paths which are, because of obvious network effects, more likely to be found in consumer markets than in markets for industrial goods or services (e.g. Shapiro \& Varian, 1999). Our findings from the semiconductor field are highly instructive, but empirical insights from other science-based fields on processes of path constitution are needed to improve their generalizability and theoretical saturation. Considering similar findings on contested, non-linear migration paths in wireless technology (Ansari \& Garud, 2009), this study may, at the very least, provide generalizable insights into organizing for path creation and path extension in other sciencebased fields. This is particularly true of the insight that path creation, even more than path extension, requires close interorganizational collaboration - based on different sets of rules and resources in the respective fields - and a specific type of collective agency. 


\section{Notes}

Initial versions of this paper were presented at the EGOS Colloquium 2005, the 2006 EIASM Workshop on 'Organizing Paths: Paths of Organizing', both in Berlin, Germany, the 2007 Annual Meeting of the Academy of Management in Philadelphia, USA, and an OTREG Workshop in Rotterdam, 2007. We are grateful for the helpful feedback received on those occasions. Moreover, we thank our interviewees for their time and patience, the Volkswagen Foundation for funding this research under grant AZ II/80308, and, last but not least, the anonymous reviewers and Raghu Garud and Paul Carlile as former and present senior editors of this journal for their most valuable comments and advice on prior versions.

1 EPL (electron projection lithography) was mainly pursued in two collaborative projects in the late 1990s. The PREVAIL project was led by IBM in cooperation with Nikon and the SCALPEL project joined the tool maker ASML with the large supplier Applied Materials and with four device makers: Lucent, Motorola, Samsung and Texas Instruments. In Europe, Infineon led an ion projection lithography (IPL) project in the EU-funded MEDEA programme.

\section{References}

Abernathy, W. J. (1978). The productivity dilemma. Baltimore, MD: Johns Hopkins University Press.

Anderson, P., \& Tushman, M. J. (1990). Technological discontinuities and dominant designs: A cyclical model of technological change. Administrative Science Quarterly, 35, 604-633.

Ansari, S., \& Garud, R. (2009). Inter-generational transitions in socio-technical systems: The case of mobile communications. Research Policy, 38, 382-392.

Arthur, W. B. (1989). Competing technologies, increasing returns, and lock-in by historical events. Economic Journal, 99, 116-131.

Barley, S. R. (1986). Technology as an occasion for structuring: Evidence from observations of CT scanners and the social order of radiology departments. Administrative Science Quarterly, 31, 78-108.

Barley, S. R., \& Tolbert, P. S. (1997). Institutionalization and structuration: Studying the links between action and institution. Organization Studies, 18, 93-117.

Behrends, H., van Burg, E., \& van Raaj, E. M. (2011). Contacts and contracts: Cross-level network dynamics in the development of an aircraft material. Organization Science, 22, 940-960.

Black, L. J., Carlile, P. R., \& Repenning, N. P. (2004). A dynamic theory of expertise and occupational boundaries in new technology implementation: Building on Barley's study of CT scanning. Administrative Science Quarterly, 49, 572-607.

Brown, C., \& Linden, G. (2009). Chips and change: How crisis reshapes the semiconductor industry. Cambridge, MA: MIT Press.

Browning, L. D., \& Beyer, J. M. (1998). The structuring of shared voluntary standards in the US semiconductor industry: Communicating to reach agreement. Communication Monographs, 65, 220-243.

Browning, L. D., Beyer, J. M., \& Shetler, J. C. (1995). Building cooperation in a competitive industry: SEMATECH and the semiconductor industry. Academy of Management Journal, 38, 113-151.

Browning, L. D., \& Shetler, J. C. (2000). Sematech: Saving the US semiconductor industry. College Station: Texas A\&M University Press.

Carayannis, E. G., \& Alexander, J. (2004). Strategy, structure and performance issues of pre-competitive R\&D consortia: Insights and lessons learned from SEMATECH. IEEE Transactions on Engineering Management, 51, 226-232.

Chiu, G. L.-T., \& Shaw, J. M. (1997). Optical lithography: Introduction. IBM Journal of Research and Development, 41(1/2), 3-5.

Chuma, H. (2006). Increasing complexity and limits of organization in the microlithography industry: Implications for science-based industries. Research Policy, 35, 394-411.

David, P. A. (1985). Clio and the economics of QWERTY. American Economic Review, 75, 332-337. 
David, P. A. (2001). Path dependence, its critics and the quest for 'historical economics'. In P. Garrouste \& S. Ioannides (Eds.), Evolution and path dependence in economic idea: Past and present (pp. 15-41). Cheltenham, UK: Edward Elgar.

DeSanctis, G., \& Poole, M. S. (2004). Capturing the complexity of advanced information technology use: Adaptive structuration theory. Organization Science, 5, 121-147.

Denzin, N. K. (1989). The research act in sociology. Chicago: Aldine.

Dhanaraj, C., \& Parkhe, A. (2006). Orchestrating innovation networks. Academy of Management Review, 31, 659-669.

DiMaggio, P. J., \& Powell, W. W. (1983). The iron cage revisited: Institutional isomorphism and collective rationality in organizational fields. American Sociological Review, 48, 147-160.

Djelic, M.-L., \& Quack, S. (2007). Overcoming path dependency: Path generation in open systems. Theory and Society, 36, 181-186.

Dosi, G. (1982). Technological paradigms and technological trajectories. Research Policy, 11, 147-162.

Doz, Y., Olk, P. M., \& Ring, P. S. (2000). Formation processes of R\&D consortia: Which path to take? Where does it lead? Strategic Management Journal, 21(special issue), 239-266.

Freeman, C. (1991). Networks of innovators: A synthesis of research issues. Research Policy, 20, 499-514.

Garud, R. \& Karnøe, P. (2001). Path creation as a process of mindful deviation. In R. Garud \& P. Karnøe (Eds.), Path dependence and creation (pp. 1-38). Mahwah, NJ: Lawrence Erlbaum Associates.

Garud, R., Hardy, C., \& Maguire, S. (2007). Institutional entrepreneurship as embedded agency: An introduction to the special issue. Organization Studies, 28, 957-969.

Garud, R., Jain, S., \& Kumaraswamy, A. (2002). Institutional entrepreneurship in the sponsorship of common technological standards: The case of Sun Microsystems and Java. Academy of Management Journal, 45, 196-214.

Garud, R., Kumaraswamy, A., \& Karnøe, P. (2010). Path dependence or path creation? Journal of Management Studies, 47, 760-774.

Ghemawat, P. (1991). Commitment: The dynamics of strategy. New York: Free Press.

Giddens, A. (1984). The constitution of society. Berkeley: University of California Press.

Golda, J., \& Philippi, C. (2007). Managing new technology risks in the supply chain. Intel Technology Journal, 11, 95-104.

Grabher, G. (1993). The weakness of strong ties: The lock-in of regional development in the Ruhr area. In G. Grabher (Ed.), The embedded firm (pp. 253-277). London: Routledge.

Greenwood, R., \& Suddaby, R. (2006). Institutional entrepreneurship in mature fields: The big five accounting firms. Academy of Management Journal, 49, 27-48.

Grindley, P., Mowery, D. C., \& Silverman, B. (1994). SEMATECH and collaborative research: Lessons in the design of high-technology consortia. Journal of Policy Analysis and Management, 13, 723-758.

Gruber, M. (2010). Exploring the origins of organizational paths: Empirical evidence from newly founded firms. Journal of Management, 36, 1143-1167.

Ham, R. M., Linden, G., Appleyard, M. M. (1998). The evolving role of semiconductor consortia in the United States and Japan. California Management Review, 40, 137-163.

Hagedoorn, J. (2002). Inter-firm R\&D partnerships: An overview of major trends and patterns since 1960. Research Policy, 31, 477-492.

Hargrave, T. J., \& Van de Ven, A. H. (2006). A collective action model of institutional innovation. Academy of Management Review, 31, 864-888.

Hoffman, A. J. (1999). Institutional evolution and change: Environmentalism and the US chemical industry. Academy of Management Journal, 42, 351-371.

Hollingsworth, J. R. (2006). A path-dependent perspective on institutional and organizational factors shaping major scientific discoveries. In J. Hage \& M. Meeus (Eds.), Innovation, science, and institutional change (pp. 423-442). New York: Oxford University Press.

Hughes, T. (1983). Networks of power. Baltimore, MD: John Hopkins University Press.

Jick, T. D. (1979). Mixing qualitative and quantitative methods: Triangulation in action. Administrative Science Quarterly 24, 602-611. 
Koch, J. (2011). Inscribed strategies: Exploring the organizational nature of strategic lock-in. Organization Studies, 32, 337-363.

Kvale, S. (1995). The social construction of validity. Qualitative Inquiry, 1, 19-40.

Langlois, R. N. (2000). Capabilities and vertical disintegration in process technology: The case of semiconductor fabrication equipment. In N. J. Foss \& P. R. Robertson (Eds.), Resources, technology and strategy (pp. 199-206). London: Routledge.

Leblebici, H., Salancik, G. R., Copay, A., \& King, T. (1991). Institutional change and the transformation of interorganizational fields: An organizational history of the US radio broadcasting industry. Administrative Science Quarterly, 36, 333-363.

LeClair, M. S. (2011). Cartelization, antitrust and globalization in the US and Europe. London: Routledge.

Leonard-Barton, D. (1995). Wellsprings of knowledge. Boston, MA: Harvard Business School Press.

Li, S. X., \& Berta, W. B. (2002). The ties that bind: Strategic actions and status structure in the US investment banking industry. Organization Studies, 23, 339-368.

Lincoln, Y. S., \& Guba, E. G. (1985). Naturalistic inquiry. London: Sage.

Linden, G., Mowery, D. C., \& Ham Ziedonis, R. M. (2000). National technology policy in global markets: Developing next-generation lithography in the semiconductor industry. Business and Politics, 2, 93-113.

Mahoney, J. (2000). Path dependence in historical sociology. Theory and Society, 29, 507-548.

Martin, R., \& Sunley, P. (2006). Path dependence and regional economic evolution. Journal of Economic Geography, 6, 395-473.

Möllering, G. (2010). Collective market-making efforts at an engineering conference. MPIfG Discussion Paper 10/2. Cologne: Max Planck Institute for the Study of Societies.

Moore, G. E. (1965). Cramming more components onto integrated circuits. Electronics, 38, 114-117.

Meyer, U., \& Schubert, C. (2007). Integrating path dependency and path creation in a general understanding of path constitution: The role of agency and institutions in the shaping of technological innovations. Science, Technology \& Innovation Studies, 3, 23-44.

Mowery, D. C., \& Rosenberg, N. (1998). Paths of innovation: Technological change in $20^{\text {th }}$-century America. Cambridge: Cambridge University Press.

Mowery, D. C. (2003). Using cooperative research and development agreements as S\&T indicators. What do we have and what would we like? Technology Analysis and Strategic Management, 15, 189-205.

Murmann, J. P., \& Frenken, K. (2006). Toward a systematic framework for research on dominant designs, technological innovations, and industrial change. Research Policy, 35, 925-952.

North, D. C. (1990). Institutions, institutional change and economic performance. Cambridge: Cambridge University Press.

Orlikowski, W. J. (1992). The duality of technology: Rethinking the concept of technology in organizations. Organization Science, 3, 398-427.

Pajunen, K. (2008). The nature of organizational mechanisms. Organization Studies, 29, 1449-1468.

Pierson, P. (2000). Increasing returns, path dependence, and the study of politics. American Political Science Review, 94, 251-267.

Poole, M. S., \& Van de Ven, A. H. (1995). Explaining development and change in organizations. Academy of Management Review, 20, 510-540.

Powell, W. W., Koput, K. W., \& Smith-Doerr, L. (1996). Interorganizational cooperation and the locus of innovation: Networks of learning in biotechnology. Administrative Science Quarterly, 41, 116-146.

Powell, W. W., \& Grodal, S. (2005). Networks of innovators. In J. Fagerberg, D. Mowery, \& R. Nelson (Eds.), The Oxford handbook of innovation (pp. 56-85). Oxford: Oxford University Press.

Pozzebon, M. (2004). The influence of a structurationist view on strategic management research. Journal of Management Studies, 41, 247-272.

Robinson, D. K. R., Rip, A., \& Mangematin, V. (2007). Technological agglomeration and the emergence of clusters and networks in nanotechnology. Research Policy, 36, 871-879.

Sakakibara, M. (2002). Formation of R\&D consortia: Industry and company effects. Strategic Management Journal, 23, 1033-1050. 
Schneiberg, M. (2007). What's on the path? Path dependence, organizational diversity and the problem of institutional change in the US economy, 1900-1950. Socio-Economic Review, 5, 47-80.

Schumpeter, J. (1942). Capitalism, socialism, and democracy. New York: Harper \& Row.

Schubert, C. (2007). Technology Roadmaps in der Halbleiterindustrie: Das Hier und Jetzt technologischer Zukünfte am Beispiel der International Technology Roadmap for Semiconductors. TUTS Working Paper 2-2007. Institute of Sociology, Technische Universität Berlin.

Shapiro, C., \& Varian, H. R. (1999). Information rules: A strategic guide to the network economy. Boston, MA: Harvard Business School Press.

Sigurdson, J. (2004). VLSI revisited: Revival in Japan. Working Paper No. 191. Stockholm School of Economics, Stockholm.

Stark, D. (1992). Path dependence and privatization strategies in East Central Europe. East European Politics and Societies, 6, 17-54.

Streeck, W., \& Thelen, K. (2005). Introduction: Institutional change in advanced political economies. In W. Streeck \& K. Thelen (Eds.), Beyond continuity: Institutional change in advanced political economies (pp. 1-39). Oxford: Oxford University Press.

Suarez, F. F. (2004). Battles for technological dominance: An integrative framework. Research Policy, 33, 271-286.

Sydow, J., \& Windeler, A. (1998). Organizing and evaluating interfirm networks: A structurationist perspective on network processes and effectiveness. Organization Science, 9, 265-284.

Sydow, J., Schreyögg, G., \& Koch, J. (2009). Organizational path dependence: Opening the black box. Academy of Management Review, 34, 689-709.

Sydow, J., Lerch, F., \& Staber, U. (2010). Planning for path dependence? The case of a network in the BerlinBrandenburg optics cluster. Economic Geography, 86, 173-195.

Thelen, K. (1999). Historical institutionalism and comparative politics. Annual Review of Political Science, 2, 369-404.

Thrane, S., Blaaberg, S., \& Møller, R. H. (2010). Innovative path dependence: Making sense of the product and service innovation in path dependent innovation processes. Research Policy, 39, 932-944.

Tushman, M., \& Anderson, P. (1986). Technological discontinuities and organizational environments. Administrative Science Quarterly, 31, 439-465.

Tushman, M., \& Rosenkopf, L. (1992). Organizational determinants of technological change: Toward a sociology of technological evolution. Research in Organizational Behavior, 14, 311-347.

Valorinta, M., Schildt, H., \& Lamberg, J.-A. (2011). Path dependence of power relations, path-breaking change and technological adaptation. Industry and Innovation, 18, 765-790.

Van Driel, H., \& Dolfsma, W. (2010). Imprinting, path dependence and metaroutines: The genesis and development of the Toyota Production System. In G. Schreyögg \& J. Sydow (Eds.), The hidden dynamics of path dependence (pp. 35-48). London: Palgrave Macmillan.

Van de Ven, A. H., \& Garud, R. (1993). Innovation and industry emergence: The case of cochlear transplants. Research on Technological Innovation, Management and Policy, 5, 1-46.

Windeler, A. (2003). Kreation technologischer Pfade: ein strukturationstheoretischer Analyseansatz. Managementforschung, 13, 295-328.

Windeler, A., \& Sydow, J. (2001). Project networks and changing industry practices-Collaborative content production in the German television industry. Organization Studies, 22 (6), 1035-1061.

Yin, R. K. (2009). Case study research: Design and methods (4th ed.). Thousand Oaks, CA: Sage.

\section{Author biographies}

Jörg Sydow is a Professor of Management at the School of Business \& Economics of the Freie Universität Berlin where he also earned his doctorate and postdoctoral qualification (Habilitation) in business administration. Currently, he is also a visiting professor at the University of Strathclyde. From 2004 until 2007 he was an international visiting fellow of the Advanced Institute of Management Research (AIM), London. He is a founding co-editor of two leading German journals, Managementforschung and Industrielle Beziehungen-The German Journal of Industrial Relations, and a member of the editorial boards of 
Organization Studies, Organization Science, Academy of Management Review and Scandinavian Journal of Management. His research interests are strategic partnering, outsourcing, inter-firm networks, regional clusters, industrial relations, innovation and project management, organization and management theory.

Arnold Windeler is Professor of Organizational Sociology at the Technische Universität Berlin. He earned his doctorate and postdoctoral qualification at the University of Erlangen-Nuremberg His research interests centre on issues of organizations, networks and social theory, especially structuration and praxis theory. His work has been published in journals including Organization Science and Organization Studies. He currently serves as a co-director of the doctoral programme on 'Innovation Society Today: The Reflexive Creation of Novelty', financed by the German Research Foundation.

Cornelius Schubert works at the Department of Sociology at the Technische Universität Berlin, where he also earned his doctoral degree. He is a postdoctoral researcher in the sociology of technology. His research interests range from ethnographic studies on the balance of routine and improvisation in technologically dense work environments to field-level analysis of innovation practices and the mutual shaping of technological and organizational dynamics.

Guido Möllering is Associate Professor of Organization and Management at Jacobs University Bremen, Germany. He earned his $\mathrm{PhD}$ at the University of Cambridge and his postdoctoral qualification (Habilitation) at the Freie Universität Berlin. His research focuses on interorganizational relationships, trust, institutional work and markets. He is book review editor of Organization Studies, associate editor of Journal of Trust Research and has published, for example, in Organization Science and Journal of International Business Studies. 